\title{
IDENTIFICAÇÃO MICROBIOLÓGICA DE BACTÉRIAS ISOLADAS EM CAVIDADE ORAL DE FALCÃO PEREGRINO (Falco peregrinus)
}

Nathana Beatriz Martins ${ }^{1}$, Caroline Lopes Queiroz ${ }^{2}$, Ana Beatriz Garcez Buiatte ${ }^{2}$, Anna Monteiro Correia Lima ${ }^{2}$, André Luiz Quagliatto Santos ${ }^{1}$.

${ }^{1}$ Laboratório de Ensino e Pesquisa em Animais Silvestres (LAPAS) da Universidade Federal de Uberlândia (UFU), Uberlândia, MG, Brasil. Faculdade de Medicina Veterinária da Universidade Federal de Uberlândia - FAMEV - UFU. Av. Mato Grosso, 3289 - Bloco 2S - Umuarama, Uberlândia - MG, 38405-314.E-mail: nathanabmartins@gmail.com

${ }^{2}$ Laboratório de Doenças Infecto-contagiosas (LDIC), Uberlândia, MG, Brasil..Faculdade de Medicina Veterinária da Universidade Federal de Uberlândia FAMEV - UFU. Av. Mato Grosso, 3289 - Bloco 2S - Umuarama, Uberlândia - MG, 38405-314.

\section{Recebido em: 02/10/2017 - Aprovado em: 21/11/2017 - Publicado em: 05/12/2017} DOI: 10.18677/EnciBio_2017B36

Devido ao seu comportamento migratório, o falcão-peregrino assume importância em relação a estudos de dispersão natural de microrganismos, por ser uma espécie topo de cadeia alimentar, tornam-se mais suscetíveis à microrganismos patógenos presentes nas presas, podendo ser um disseminador desses patógenos. O grande deslocamento que realizam estes animais, as presas possivelmente contaminadas e a escassez de literatura geram a necessidade de verificar a presença de microorganismos através do isolamento e tipificação bacteriana, além de conhecer o papel destas aves na disseminação deste patógeno ao meio ambiente. O presente estudo objetivou relatar as bactérias da cavidade oral em um falcão peregrino (Falco peregrinus), resgatado em ambiente urbano, sem histórico prévio, apresentando lesões na cavidade oral, com presença de secreção. Procedeu-se a coleta do material da secreção da cavidade oral e posterior análise microbiológica e bioquímica. Foram identificadas colônias características de Staphylococcus spp., Escherichia coli, Enterobacter aerogenes e Enterobacter cloacae. Todos os agentes isolados pertencem a microbiota normal de rapinantes, porém são capazes de causar infecção quando há depressão do sistema imunológico. A E. coli ainda não havia sido relacionada à infecções de cavidade oral, com formação de placas. Portanto, a predominância destas bactérias nos processos infecciosos está diretamente relacionada com o caráter oportunista assumido pela microbiota bacteriana normal. O falcão peregrino, por ser uma ave migratória, pode albergar micro-organismos patógenos adquiridos ao longo de sua rota migratória, tornando-se um potencial disseminador desses microrganismos.

PALAVRAS-CHAVE: ave migratória, isolamento, placas orais. 


\section{MICROBIOLOGICAL IDENTIFICATION OF ISOLATED BACTERIA IN ORAL CAVITY OF PEREGRINE FALCON (Falcoperegrinus) ABSTRACT}

Dueto your migration behavior, Peregrine falcon assumes importance in relation to natural dispersal of microorganisms, for being a species top of the food chain, they become more susceptible to microbial pathogens present in prey, and can be a disseminator of these pathogens. The great shift that perform these animals, possibly contaminated prey and the paucity of literature generate the need to check for the presence of microorganisms through the insolation and bacterial typing, in addition to meeting the role of these birds in dissemination this pathogen. The present reportaimed to identify bacteria from the oral cavity in a Peregrine Falcon (Falco peregrinus), rescued in urban environment, without a prior history, present in lesions in the oral cavity, with presence of secretion. Collection was made of material with a cotton swab sterile alginatado of oral cavity secretion and subsequent microbiological and biochemical analysis. Colonies were identified characteristics of Staphylococcus spp., Escherichia coli, Enterobacter aerogenes and Enterobacter cloacae. All isolated agents belong the normal microbiota of raptors, but are capable of causing infection when there is depression of the immune system. The $E$. coli had not yet been linked to infections of the oral cavity, with formation of plaques. Therefore, the prevalence of these bacteria in infectious processes is directly related with the opportunistic character assumed by the normal bacterial microbiota. The Peregrine Falcon, for being a migratory bird, can accommodate microorganisms pathogens acquired along your flyway, making it a potential disseminator of such micro-organisms.

KEYWORDS: isolation, migratory bird, oral cavity.

\section{INTRODUÇÃO}

O Brasil está entre os países com a mais rica avifauna no mundo, juntamente com Colômbia e Peru (REMSEN et al., 2015), além de ser o país com o maior número de espécies descritas na última década e com o maior número de espécies globalmente ameaçadas de extinção (CBRO, 2015).

Aves de rapina ou rapinantes são aves carnívoras das ordens Accipitriformes, Falconiformes e Strigiformes. Estas aves predadoras capturam suas presas com as garras e são denominadas por possuírem características semelhantes, como garras curvas e afiadas e bicos fortes, recurvados e pontiagudos. Estas características anatômicas, somadas à visão desenvolvida, adaptada para a procura e a visualização das presas,conferem a este grupo de aves grande capacidade de caça (JOPPERT, 2015).

Os rapinantes de hábitos diurnos estão classificados nas ordens Cathartiformes, sendo os abutres e urubus, Acciptriformes compreendida pelas águias e gaviões e Falconiformes, representada pelos falcões. A ordem que compreende os animais de hábitos noturnos como as corujas é a Strigiformes(FERGUSON-LEES; CHRISTIE, 2001; PIACENTINI et al, 2015).

Segundo o Comitê Brasileiro de Registros Ornitológicos (CBRO 2015), no Brasil, há seis espécies da ordem Cathartiformes, 68 espécies de Falconiformes e 23 espécies da ordem dos Strigiformes. Destes, 9 espécies realizam migrações regulares. Algumas espécies como o falcão-peregrino (Falcoperegrinus), podem percorrer mais de 22 mil km até seu destino final (MENQ, 2015).

O falcão-peregrino (Falco peregrinus), pertencente à família Falconidae, é considerado o maior representante do gênero Falco nas Américas, é oriundo do 
hemisfério norte e chega ao Brasil como ave migratória (SICK 1997; MENDONÇA, 2015). O falcão-peregrino (Falco peregrinus) é um falcão cosmopolita e o rapinante migratório mais conhecido, chega ao Brasil entre os meses de outubro e abril. É possível observá-lo em quase todas as regiões, porém é encontrado com mais facilidade em grandes centros urbanos e cidades costeiras (MENQ, 2015).

Há quatro subespécies conhecidas no continente americano, das quais apenas duas chegam ao Brasil durante migração, sendo o Falco peregrinus tundrius e o Falco peregrinus anatum. O tundrius é menor e é a subespécie norte-americana que mais responde aos estímulos migratórios com deslocamentos de longa distância. O F. p. anatum tem uma distribuição mais ampla, abrangendo áreas de amplitudes térmicas variáveis e menos extremas, e dado a isso, nem todos chegam a se deslocar tanto do seu ponto de origem, mas os que se deslocam mais conseguem chegar ao Brasil (MENQ, 2015).

O falcão-peregrino, devido ao seu comportamento migratório, pode se comportar como dispersador natural de microrganismos, já que a migração de algumas subespécies de Falco peregrinus dentro continente americano, podem ter suas rotas passando do extremo norte ao extremo sul do continente, migrando por ambientes altamente diversificados (MENQ,2015).

As doenças infecciosas são causas comuns de morte em rapinantes. Muitas espécies de bactérias são isoladas de aves de rapina, porém informações sobre a distinção entre microbiota normal e microbiota contaminante ou exógena são escassas. Microrganismos oportunistas podem causar enfermidades em hospedeiros com comprometimento do sistema imune (COOPER, 2002; JOPPERT 2015).

Bactérias pertencentes à família Enterobacteriaceae são consideradas como importantes patógenos aviários. São micro-organismos Gram negativos, que fazem parte da microbiota normal do sistema digestório, porém podem torna-se patogênicos (SEGABINAZI, 2004). A Escherichia coli faz parte da microbiota do trato gastrointestinal de animais de sangue quente, sendo considerada comensal, podendo existir grandes diferenças entre as cepas, as cepas consideradas patogênicas para as aves são conhecidas por APEC (avian pathogenic escherichia coli), que causa colibacilose em aves, relacionada a depressão do sistema imune (FUDGE, 2001).

RELATO DE CASO

Um espécime de falcão-peregrino (Falco peregrinus), macho, jovem, aproximadamente 1 ano, foi resgatado em ambiente urbano em Uberlândia - Minas Gerais, com incapacidade de voo e encaminhado pela Polícia Ambiental ao Laboratório de Ensino e Pesquisa em Animais Silvestres (LAPAS) do Hospital Veterinário da Universidade Federal de Uberlândia (UFU).

O animal foi devidamente contido para coleta de dados morfométricos. Utilizando-se um paquímetro, obteve-se as medidas de cumem, diâmetro do tarso, tarso, bico. Com a fita métrica, foram coletados dados de envergadura, comprimento total e cauda. Uma balança com precisão de $0,5 \mathrm{~g}$ foi utilizada para aferição do peso. Os dados biométricos estão representados na Tabela 1. 
Tabela 1. Morfometria de um espécime de Falco peregrinus encontrado em zona urbana de Uberlândia - MG.

\begin{tabular}{l|l}
\hline \multicolumn{1}{c|}{ Parâmetros } & \multicolumn{1}{c}{ Dados } \\
Peso & $390 \mathrm{~g}(\mathrm{I}) ; 370 \mathrm{~g}(\mathrm{O})$ \\
Comprimento total & $39,3 \mathrm{~cm}$ \\
Cauda & $16 \mathrm{~cm}$ \\
Cabeça & \\
Bico & $7,3 \mathrm{~cm} \times 6,2 \mathrm{~cm}$ \\
Pé & $24,26 \mathrm{~mm} \times 8,25 \mathrm{~mm}$ \\
Tarso & $83,85 \mathrm{~mm}$ \\
Diâmetro tarso & $40,8 \mathrm{~mm}$ \\
Envergadura & $16,98 \mathrm{~mm}$ \\
& $90 \mathrm{~cm}$ \\
\hline
\end{tabular}

(I) Inicial: peso de chegada do animal; (O) o peso após óbito.

$\mathrm{Na}$ avaliação clínica, o animal apresentou-se apático, prostrado, olhos caídos, presença de disfagia e diarreia. Na cavidade oral, observou-se secreção de aspecto caseoso, com início de formação de placas (Figura 1). Procedeu-se a coleta de amostras da secreção com auxílio de um swab com algodão alginatado esterilizado. A amostra foi armazenada em tubo plástico contendo o meio de transporte semisólidoStuart e encaminhadas para o Laboratório de Doenças Infectocontagiosas da Universidade Federal de Uberlândia.

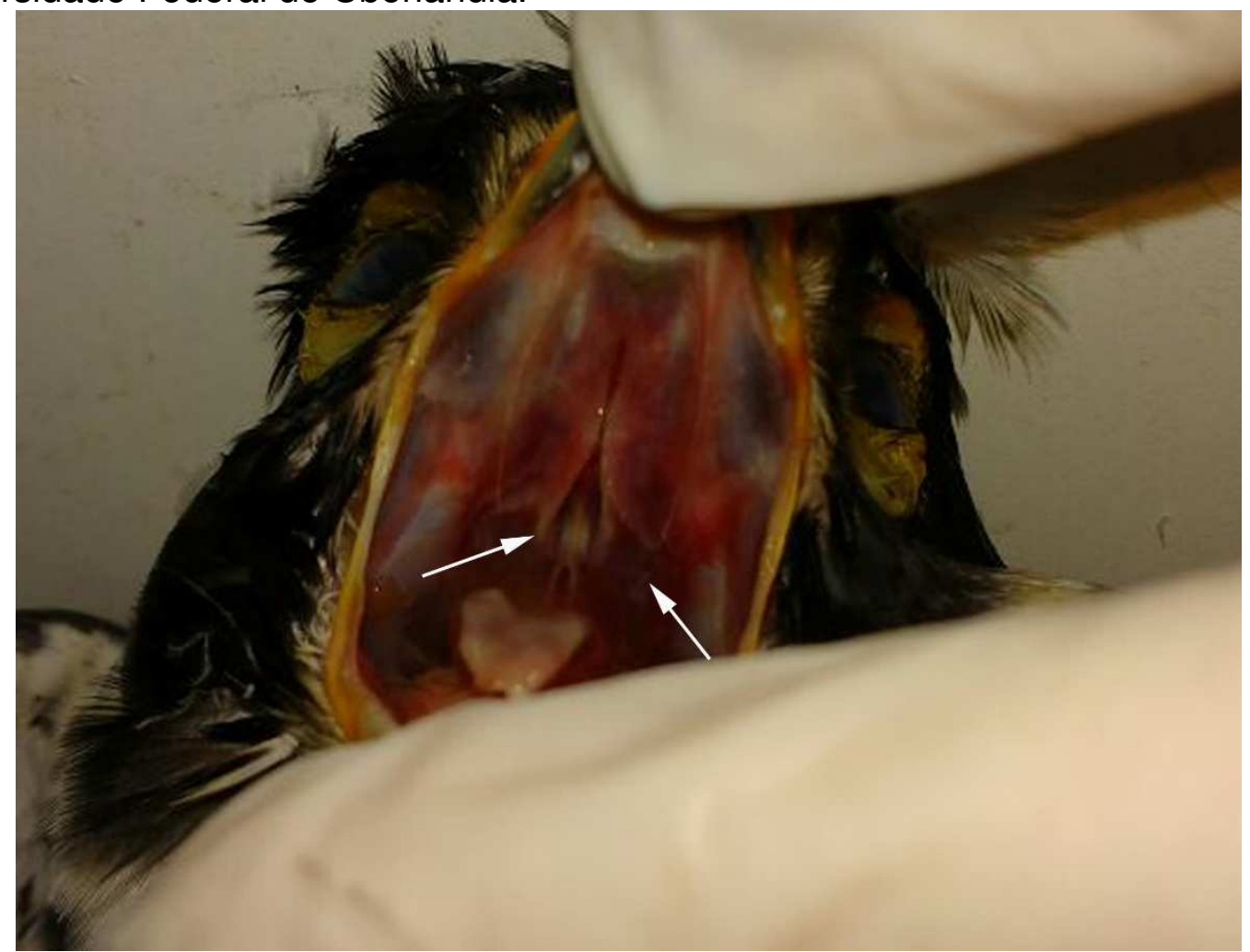

Figura 1. Um espécime de falcão peregrino (Falco peregrinus) apresentando lesões na cavidade oral, com áreas hiperêmicas (setas) e formação de secreção.

Fonte: Arquivo pessoal 
A amostra foi transferida para um tubo contendo caldo Tioglicolato, sendo este um meio altamente nutritivo, que auxilia o crescimento de microrganismos. Posteriormente, a amostra foi submetida à incubação em estufa bacteriológica a $37^{\circ} \mathrm{C}$ durante 24 horas, conforme descrito por Oplustil (2004).

Para isolar as colônias bacterianas, as amostras foram semeadas com auxílio de uma alça de platina em placas de Petri, uma contendo o Ágar sangue e a outra o Ágar Mac Conkey, utilizando-se a técnica de esgotamento em Ágar. As placas semeadas foram colocadas em estufa bacteriológica a $37^{\circ} \mathrm{C}$ por 24 horas para incubação, conforme Quinn et al. (2004). A partir de colônias do Ágar-sangue foi feita a coloração de Gram para identificação de bactérias Gram positivas e negativas.

As colônias crescidas no Ágar MacConkey foram identificadas através de testes bioquímicos em determinados meios como: Vermelho de fenol, Lisina, Fenilalanina, Citrato de Simmons, Uréia e SIM (produção de ácido sulfídrico, indol e motilidade), que têm como finalidade a triagem de colônias que crescem em meios seletivos para bactérias Gram negativas, pertencentes à família Enterobacteriaceae. Utilizou-se um meio para cada colônia diferente do Ágar MacConkey, para identificação de cada gênero ou espécie bacteriana (Figura 2).

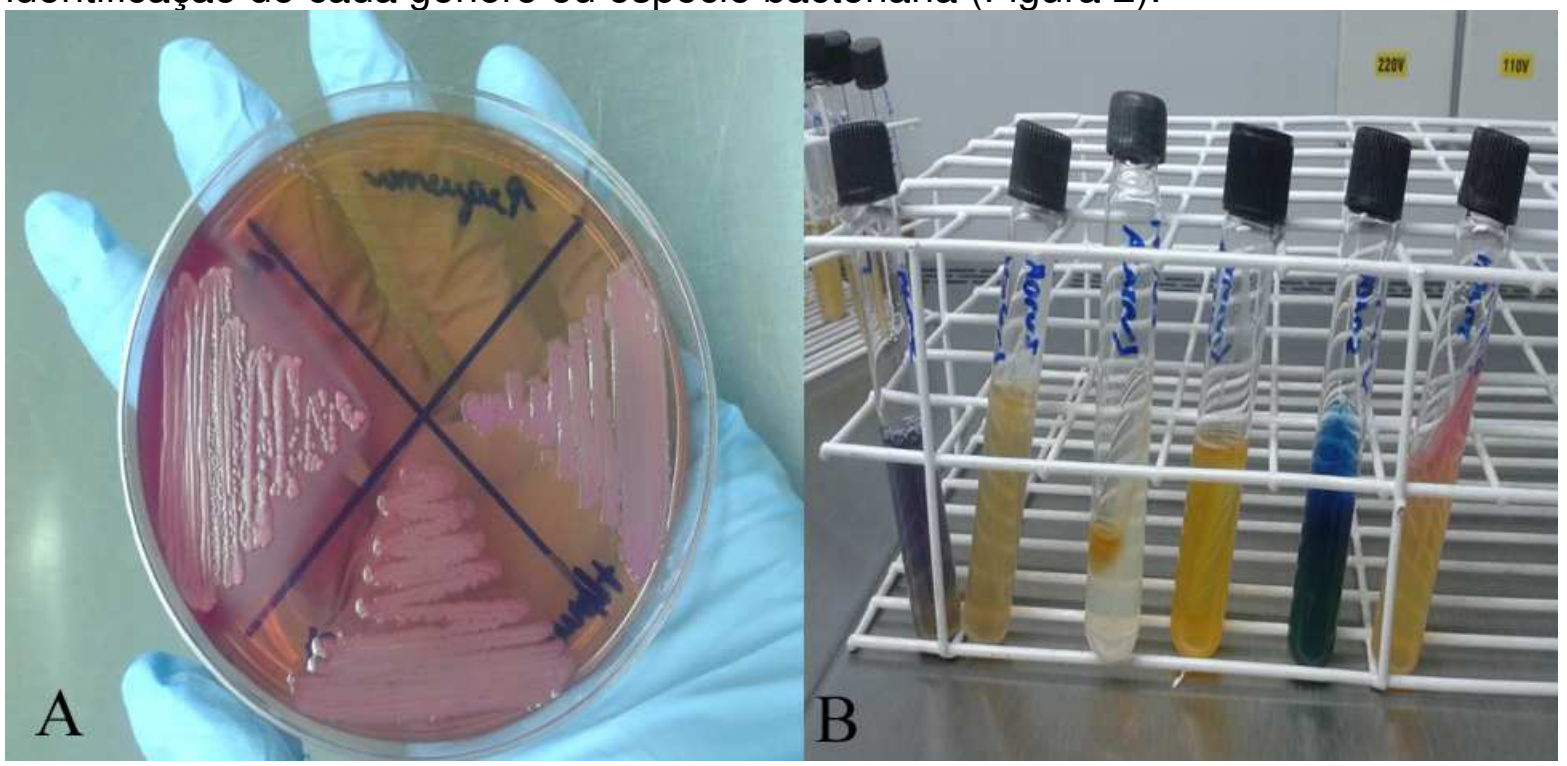

Figura 2. (A) Colônias crescidas em ágar MacConkey: no canto esquerdo Escherichia coli, na parte inferior Enterobacter cloacae e no canto direito Enterobacter aerogentes. (B) Testes bioquímicos para identificação de Enterobacter cloacae, da esquerda para a direita: prova da descarboxilação da lisina negativo, prova do SIM (motilidade positivo, prova de $\mathrm{H}_{2} \mathrm{~S}$ negativo e prova do indol negativo), prova de fenilalanina negativo, produção de gás positivo, prova do Citrato de Simmons positivo, prova da produção de urease negativo.

\section{RESULTADOS E DISCUSSÃO}

Após o cultivo, foram identificadas colônias características de Staphylococcus spp. não hemolíticas, Escherichia coli, Enterobacter aerogenes e Enterobacter cloacae, confirmadas posteriormente por testes bioquímicos. Além destas, também foi observado o crescimento de um micro-organismo leveduriforme, que não foi identificado posteriormente.

De acordo com Sorum e Sunde (2001), os micro-organismos mais comumente relacionados à quadros de infecção em rapinantes são os Bacteroides 
spp., Fusobacteriumspp., Clostridium spp., Peptostreptococcus spp., Enterobacter spp., Enterococcus spp., Mycobacterium avium, Pasteurellaspp., Escherichia coli, Shigellaspp., Salmonella spp. e Staphylococcus spp., os achados do presente estudo corroboram com os dados de literatura.

A família Enterobacteriaceae compõe-se de grupos de micro-organismos Gram negativos, associados a diversos processos infecciosos em aves de rapina. A sua nomenclatura é referente à sua localização habitual ser o intestino, portanto frequentemente associada a infecções intestinais, mas podem ser encontradas em quase todos os ambientes (GUERRERO et al., 2014). A E. colipertence à família Enterobacteriaceae, é um bacilo Gram negativo que faz parte da microbiota normal do trato gastrointestinal de aves e mamíferos. Nas aves, as infecções por E. coli tende a ser localizada e quando há comprometimento do sistema imunológico ou cepas virulentas, ocorre infecção sistêmica (JOPPERT, 2015).

Em rapinantes, as infecções por $E$. coli estão comumente associadas a abscessos hepáticos, aerossaculite, pericardite purulenta, enterite, pancreatite, pneumonia e nefrite. Porém, as septicemias por E. coli estão relacionadas a pós traumas, como fraturas e feridas por projétil (COOPER, 2002; JOPPERT, 2015). Entretanto, a E. coli ainda não havia sido relacionada a infecções de cavidade oral, com formação de placas.

Outros micro-organismos são capazes de provocar lesões semelhantes às observadas por E. coli, como Pseudomonas spp., Proteus spp., Acinetobacter spp., Enterobacter spp., Klebsiella spp., sendo necessário o isolamento e a identificação do agente para o diagnóstico diferencial (JOPPERT, 2015). Pode haver associação entre estes micro-organismos e E. coli, como ocorreu no presente estudo, onde houve associação de duas espécies de Enterobacter, E. coli e Staphylococcus.

Os animais silvestres, principalmente as aves, por serem sentinelas no reflexo do impacto da atividade humano no meio ambiente e também por se portarem como reservatórios de micro-organismos, são importantes em relação a resistência antimicrobiana. Além disso, podem disseminar patógenos durante a migração, podendo afetar inclusive os seres humanos (GUENTHER et al., 2010; BONNEDAHL; JÄRHULT, 2014; ROUFFAER; HAESEBROUCK; MARTEL, 2014; SOUSA et al., 2014 GOULART, 2015). De acordo com Ahmed et al. (2007), animais silvestres em cativeiro, são responsáveis por cerca de $70 \%$ das doenças emergentes, incluindo o aumento da resistência a antimicrobianos.

Portanto, o conhecimento da microbiota residente ou transitória que compõe as diferentes áreas do organismo, torna-se imprescindível para a compreensão das doenças infecciosas que acometem homens e animais (TORTORA et al., 2016). Apesar de serem micro-organismos pertencentes à microbiota normal, estas podem provocar lesões graves, comprometendo alimentação adequada do animal. Destacando-se a importância da espécie em estudo por ser uma ave migratória e a escassez de estudos na literatura, torna-se necessário verificar a presença de microorganismos através do isolamento e tipificação bacteriana, além de conhecer o papel destas aves na disseminação deste patógeno ao meio ambiente.

\section{CONCLUSÃO}

Foram identificadas colônias características de Staphylococcus spp., Escherichia coli, Enterobacteraerogenese Enterobactercloacaena cavidade oral de um falcão peregrino (Falco peregrinus) apresentando lesões em cavidade oral, com presença de secreção. Todos os micro-organismos isolados são pertencentes à 
microbiota normal e a infecção oral pode ter sido gerada por desequilíbrio imunológico e físico.

\section{REFERÊNCIAS}

AHMED, A. M.; MOTOI, Y.; SATO, M.; MARUYAMA, A.; WATANABE, H.; FUKUMOTO, Y.; SHIMAMOTO, T. Zoo animals as reservoirsofGram-negative bactéria harboringintegronsandantimicrobialresistance genes. Appliedand Environmental Microbiology, v. 73, n. 20, p. 6686-6690, 2007. Disponível em: <http://www.ncbi.nlm.nih.gov/pmc/articles/PMC2075039>. Acesso em: 15 set. 2017. doi: 10.1128/AEM.01054-07.

BONNEDAHL, J.; JÄRHULT, J. D. Antibioticresistance in wildbirds. Upsalajornal of medical sciences, v. 9734, n. January, p. 1-4, 2014. Disponível em: $<$ http://www.tandfonline.com/doi/full/10.3109/03009734.2014.905663> Acesso em: 29 set. 2017. Doi: $10.3109 / 03009734.2014 .905663$

CBRO - Comite Brasileiro de Registros Ornitológicos 2015. Listas das aves do Brasil. Versão 13/3/2015. Disponível em <http:/www.cbro.org.br>. Acesso em 04 ago. 2017.

COOPER, J. E. Birdsofpreyhealth\&disease. 3. ed. Oxford: Blackwell Science, 2002. 345p.

FERGUSON-LEES, J.; CHRISTIE, D.A. Raptorsofthe world. Boston: HoughtonMifflinCo, 2001. $992 \mathrm{p}$

FUDGE, A. M. Diagnosisandtreatmentofavianbacterialdiseases. Seminars in AvianandExotic Pet Medicine, v.10, ed.1, p.3-11, 2001. Disponível em: https://www.ncbi.nlm.nih.gov/pubmed/24852141 Acesso em 29 set. 2017. doi:10.1053/saep.2001.1954

GUENTHER, S.; GROBBEL, M.; LÜBKE-BECKER, A.; GOEDECKE, A.; FRIEDRICH, N.D.; WIELER, L.H.; EWERS, C. Antimicrobialresistance profiles of Escherichia colfrom common Europeanwildbirdspecies. VeterinaryMicrobiology, v. 144, n. 1-2, p. 219-225, 2010. doi: 10.1016/j.vetmic.2009.12.016

GUERRERO, P. P. SANCHEZ, F. G. SABORIDO, D. G. LOZANO, I. G. Infecciones por enterobacterias. Medicine, v. 11, n. 55, p. 3276-82. 2014. doi: 10.1016/S03045412(14)70768-1

GOULART, M. D. A. Parâmetros hematológicos, bioquímicos e pesquisa de cepas produtoras de ESBL e carbapenemases em aves de rapina em cativeiro no Brasil.Dissertação de Mestrado. Universidade Federal do Paraná. Programa De Pós-Graduação Em Ciências Veterinárias. 2015. 153 f. Disponível em: <http://www.acervodigital.ufpr.br/bitstream/handle/1884/42898/R\%20-\%20D\%20\%20MIURIEL\%20DE\%20AQUINO\%20GOULART.pdf? sequence=18isAllowed $=y$ > .

JOPPERT, A.M. Accipitriformes, Falconiformes e Strigiformes (Gaviões, Águias, Falcões e Corujas) In: Cubas Z.S., Silva J.C.R., Catão Dias J.L. (Eds). Tratado de 
animais selvagens - Medicina veterinária.2ed. São Paulo: Roca Ltda, pp. 68-85. 2014.

MENDONÇA S. V. Caracterização hematológica, bioquímica, morfométrica e microbiológica de falcões peregrinos (Falco peregrinus) de vida livre. Dissertação de Mestrado. Universidade Estadual do Ceará. Programa De PósGraduação Em Ciências Veterinárias. 2015. 56 f. Disponível em: < http://www.uece.br/ppgcv/dmdocuments/SanjayMendon\%C3\%A7a_Disserta\%C3\%A7\%C3\% A3o.pdf>.

MENQ, W. Aves de Rapina Brasil: Aves de Rapina Migratórias. Disponível em: http://www.avesderapinabrasil.com.br/arquivo/artigos/Aves de rapina migratorias.pdf. 2015.

OPLUSTIL, C.P. Procedimentos básicos em microbiologia clínica, $2^{\mathfrak{a}}$ ed., Sarvier, São Paulo, 340 pp. 2004.

PIACENTINI, V. D. Q., ALEIXO, A., AGNE, C. E., MAURÍCIO, G. N., PACHECO, J. F., BRAVO, G. $\quad$ A., $\quad$ SILVEIRA, L. AnnotatedchecklistofthebirdsofBrazilbytheBrazilianOrnithological Records Committee / Lista comentada das aves do Brasil pelo Comitê Brasileiro de Registros Ornitológicos. Revista Brasileira de Ornitologia, Rio de Janeiro, . 23, n. 1, p.91298, 2015.

QUINN, L.M., DICKINS, R.A., COOMBE, M., HIME, G.R, BOWTELL, D.D., RICHARDSON,

H.DrosophilaHfpnegativelyregulatesdmycandstgtoinhibitcellproliferation.

Development, doi: 131:1411-1423. 2004.

REMSEN, J. V. JR.; ARETA J. I.; CADENA, C. D.; JARAMILLO, A.; NORES, M ; PACHECO, J. F.; PÉREZ-EMÁN, J.; ROBBINS, M. B.; STILES, F. G.; STOTZ, D. F. \& ZIMMER K. J.A classificationofthebirdspeciesof South America. American Ornithologists' Union.Disponível em: http://www.museum.Isu.edu/ Remsen/SACCBaseline.html Acessado em 29 set. 2017. 2015

ROUFFAER, L. O.; HAESEBROUCK, F.; MARTEL, A. Extended-spectrum $\beta-$ lactamase-producingEnterobacteriaceaeisolatedfromfecesofFalconidae, Accipitridae, andlaridae in bird rescue centers in Belgium. Journal of wildlife diseases, v. $50, \mathrm{n}$. 4, p. 957-60, 2014. doi: 10.7589/2013-08-208.

SEGABINAZI, S.D. Presença de bactérias de família Enterobacteriaceae nas superficies externa e interna de Alphitobius diapenerius (panzer) oriundos de granjas avícolas dos Estados do rio Grande do Sul e Santa Catarina. Santa Maria. Dissertação (MESTRADO).Universidade Federal de Santa Maria. 105 p. 2004.

SICK, H. Ornitologia Brasileira. Rio de Janeiro: Nova Fronteira, P. 263-267, 1997. 
SOUSA, M.; SILVA, N.; IGREJAS, G.; SILVA, F.; SARGO, R.; ALEGRIA, N. et al. Antimicrobialresistancedeterminants in Staphylococcus spp. recoveredfrombirdsofprey in Portugal. Veterinary Microbiology, v. 171, p. 436-440, 2014.doi: 10.1016/j.vetmic.2014.02.034.

SORUM, H.; SUNDE, M. Resistancetoantibiotics in the normal flora ofanimals. VeterinaryResearch, v. 32, p. 227-241, 2001. Disponível em: <http://www.ncbi.nlm.nih.gov/pubmed/11432415>. Acesso em: 11 set 2017. doi: 10.1051/vetres:2001121.

TORTORA, G. J., CASE, C. L., \& FUNKE, B. R.Microbiologia-12ª Edição. Artmed Editora. 2016. 